\title{
Psychological and Pedagogical Support of the Educational Process in the Conditions of Informatization of Education
}

\author{
Gennady Kiselev \\ Moscow Regional Socioeconomic Institute \\ Vidnoe, Russia \\ E-mail:kgm65@yandex.ru
}

\author{
Albina Chervova \\ Ivanovo State University \\ Shuya, Russia \\ E-mail:kgm65@yandex.ru
}

\begin{abstract}
The paper is devoted to topical issues of professional activity of psychological and pedagogical education specialists in the informational educational space. This includes the peculiarities of psycho-pedagogical support of the educational process in the conditions of informatization of education. The paper describes the historical background of the emergence of psychological and pedagogical support and sets out the need for professional training in the information educational environment.
\end{abstract}

Keywords-psychological and pedagogical education; psychological and educational support; information educational environment; informatization

\section{INTRODUCTION}

The new legislation in the field of education, as well as the modern socio-economic conditions, have led to a set of new requirements for the level and content of continuous professional education, having changed the criteria of social requirements for the nomenclature of directions and specializations of training and the quality of graduates of higher educational institutions. The modern society faces a sharp increase in the need for highly qualified specialists in socially important professions adapted to the conditions dictated by the global information processes. The main task in the preparation of graduates is proficiency not only in their subject area, but also in advanced technologies that allow them to optimize their professional activities. On the one hand, the intensive development of the information worldview of the individual, his or her preparation and adaptation to working conditions in the information socioeconomic space opens up new opportunities for the specialist to access information and knowledge, but on the other hand, it carries numerous risks and dangers: there are possible negative consequences of the intensive introduction of information technologies and information resources into everyday life and professional activity of a person. Therefore, it must be recognized that along with the huge positive impact of computerization and informatization of society, the growth of information and technology capabilities also increases the risks of negative consequences of global informatization. Consequently, there is a need to solve the global pedagogical problem - training people for the new conditions of professional activity in an environment with a developed information infrastructure, teaching them how to effectively use information technologies and information resources while protecting themselves from the possible negative consequences. At the same time, it is also important to create a comfortable, ecological, psychologically healthy and health-saving educational environment. Under the given conditions, the importance of pedagogical psychologists, whose professional activity is aimed at psychological and pedagogical support of the educational process which is based on developed information and technological infrastructure, is especially important.

\section{PSYCHOLOGICAL AND PEDAGOGICAL SUPPORT OF THE EDUCATIONAL PROCESS}

Psychological and pedagogical support, as a special area of the culture of interaction between a teacher-psychologist with students in the educational process, emerged relatively recently. This is a fairly young, but already well-established direction in education, which arose in the framework of providing students with qualified psychological and pedagogical assistance in overcoming learning difficulties, information loads, emotional-volitional disorders, problems arising in relationships with others, with the choice of the educational direction, etc. The culture of such interaction acquired special significance and popularity among numerous models of psychological service in the education system at the end of the $20^{\text {th }}$ century.

The theoretical aspects of the concept "psychological and pedagogical support" have already been adequately covered in psychological, pedagogical, philosophical and other kinds of literature. Thus, in psychological literature such support is considered as a complex technology of socio-psychological assistance to an individual (M.R. Bityanova, L.M. Shipitsina, I.S. Yakimanskaya and others). These scientists state that the most important aspect of psychological support is the positive relationship among all the participants of the educational process, such as directors, teachers, educators and students, who influence the realization of intellectual potential and guarantee the trainee friendly relations, support and help. This way the educational environment obtains a special culture in solving the tasks of teaching, upbringing and developing 
students. The problems of the organization of qualitative psychological and pedagogical support, its content aspects and features are fully and thoroughly disclosed in the studies of M.R. Bityanova, I.V. Dubrovina, L.M. Shipitsyna, I.S. Yakimanskaya and others. The theoretical and methodological foundations of the system of psychological and pedagogical support have been studied and sufficiently covered in scientific literature. According to S.G. Kosaretsky they are:

- The person-centered approach of IS. Yakimanskaya and others;

- The anthropological paradigm of V.I. Slobodchikov and E.I. Isayev;

- The concept of mental and psychological health of children by I.V. Dubrovina;

- The paradigm of developing education of D.B. Elkonin and V.V. Davydov;

- The project approach in the organization of psychological, medical and social support of M.R. Bityanova, E.V. Burmistrova, A.I. Krasilo [2] [3] [4] [5].

Pedagogical psychologists consider the idea of psychological and pedagogical support to be productive almost at all the levels of the educational process. According to E.A. Kozyreva, "... support is a system of professional activities of the teacher-psychologist, aimed at creating conditions for positive development of relations between children and adults in the educational situation, psychological and mental development of the child with an orientation to the zone of the nearest development" [6].

Thus, summarizing all of the aforesaid, we come to defining the essence of psychological and pedagogical support as a method that provides the creation of conditions for making optimal decisions in different situations of life choices and help the subject in making decisions in difficult situations of life choices, allowing the subject to make a decision and be responsible for its implementation. The purpose of support is to create a comfortable environment, as close to reality as possible, for the comprehensive development of the individual.

Analyzing everything mentioned above, we mean by psychological and pedagogical support in our work "... a holistic, continuous process of researching a student's personality, its formation, creating conditions for selfrealization and development in all spheres of activity, adaptation in the society at all age stages of education, carried out by all participants of the educational process in interaction situations" [7].

This is a system of professional activity of the teacherpsychologist, aimed at creating socio-psychological conditions for successful learning and psychological development in various situations of educational interaction.

\section{PSYCHOLOGICAL AND PEDAGOGICAL SUPPORT IN THE CONDITIONS OF EDUCATION INFORMATIZATION}

In terms of our research, we are interested in the aspects of psychological and pedagogical support of the educational process in the context of the informatization of the education system and the professional activity of the teacherpsychologist in the information educational environment.

As is known, the main areas of work of specialists in psychological and pedagogical support are [8]:

- Psychological diagnosis (research of personal qualities and features of students, mental processes, their influence on the educational process);

- Psychological counseling (practical psychological help in various life situations);

- Corrective and developing activities (activities for the development of mental processes, personal characteristics, etc.);

- Psychological education (covering the problems and offering proposals for their rational solution);

- Participating in developing the conceptual framework of the educational institution;

- Maintenance of documentation in the prescribed form.

The use of information technologies can have a significant impact on the contents, forms and methods of psychological and pedagogical support in all of the abovementioned directions [9].

For this purpose, the psychologist-educator must be competent in the use of computer technologies in the modern information educational environment. They are:

- using information technologies as a means of teaching, which allows to improve the teaching process comprehensively, improve its quality and efficiency;

- using ICT for creative development of students;

- using ICT as a means of optimizing the processes of psychodiagnostics, testing, control, correction, etc.;

- using communication tools for the transfer and acquisition of progressive pedagogical experience, for obtaining unlimited access to methodological and educational literature;

- using modern information technologies for organizing effective intellectual leisure of students

- improving the management of the educational institution and the educational process on the basis of the use of information and communication technologies.

The possibilities of modern computer technologies in the educational space are largely adequate to the organizational, pedagogical and methodological needs of education: 
- Computational - fast and accurate conversion of any kinds of information (numerical, text, graphic, sound, etc.);

- Transducer - the ability of a computer to receive and deliver information in a variety of forms (if appropriate devices are available);

- Combinatorial — the ability to remember, store, structure, sort out large amounts of information, quickly find the necessary information;

- Graphic - the ability to present the results of work in visual, graphic, video and animation forms;

- Modeling — the possibility of constructing information models of real objects and phenomena.

These computer capabilities can contribute not only to the development of the child's personality, but also to the identification, development of his or her abilities, the formation of skills and the desire to learn, and the creation of conditions for effective psychological and pedagogical support of the entire teaching and upbringing process.

The structure of the methodical system consists of the bases, core and consequences and is based on the idea of continuously forming students' information culture in higher education with the integration of the information block disciplines and the block of psychological and pedagogical disciplines. For implementing the system, we have developed the textbook "Information Technologies in Teacher Education" which is recommended by the certification body for educational activities "Center for Professional Education Quality" as a textbook for university students studying for a bachelor in the direction of "Pedagogical Education".

The modern teacher-psychologist in an environment with well-developed and widely used information technologies must possess a high-level information culture, competences necessary both for increasing the effectiveness of professional activity and for correctly educating members of the information society and also for possible elimination of negative psychological consequences of intensive information processes [10].

At the same time, the studies conducted by us for a number of years have shown that, despite the considerable expansion of scientific work in the field of comprehensive training of psycho-pedagogical personnel, the formation of information and communication competencies and the information culture in general, it cannot be said that the modern system of training specialists for psychological and pedagogical support of the educational process in the information educational environment meets the requirements of the society. Practice shows that the majority of pedagogical psychologists who received professional education in times of absence or insufficient use of personal computers, there is a certain conflict between their life experience where there was no computer and the reality where computer technologies are conquering all the new areas of human activity. In short, the lack of the necessary training for teachers-psychologists to work with the means of computer technologies remains one of the main reasons for the lack of readiness for effective work in the information and communication educational environment, which implies creating a comfortable, health-saving educational environment, reducing the risks of negative consequences of intensive use of ICT, protecting students from the negative consequences of excessive computer use.

\section{CONCLUSION}

To achieve the new educational goals, for a number of years we have been developing a methodological system for the formation of the information culture among future teachers-psychologists in the information educational environment of universities with new conditions of preparation for work in the educational environment with a developed information technology infrastructure in compliance with the conditions of intensive informatization of all spheres of social life and the educational system. The structure of the methodical system consists of the bases, core and consequences and is based on the idea of continuously forming students' information culture in higher education with the integration of the information block disciplines and the block of psychological and pedagogical disciplines. For implementing the system, we have developed the textbook "Information Technologies in Teacher Education" which is recommended by the certification body for educational activities "Center for Professional Education Quality" as a textbook for university students studying for a bachelor in the direction of "Pedagogical Education". The textbook systematizes the material for the formation of ICTcompetence of bachelors in the direction of psychological and pedagogical education. The content is focused on the federal state educational standards of higher education and meets the requirements that are mandatory for the implementation of the basic educational program of the bachelor's degree in the field of training "Psychological and pedagogical education". In addition, there are authorial programs for improving the qualifications of pedagogical workers in terms of using information technologies in the educational process, as well as laboratory case studies "Modern Information Technologies" for practical work.

\section{REFERENCES}

[1] M.R. Bityanova, Organization of psychological work at school [Text] / MR. Bityanova. Moscow: Perfection, 1997, 298 p. (Practical Psychology in Education).

[2] L.M. Shipitsyna, A.A. Khilko, Yu.S. Galliamova, R.V. Demyanchuk, N.N. Yakovleva, Complex support of children of preschool age / Under scientific. Ed. prof. L. M. Shipitsyna. SPb.: 2008.

[3] S.G. Kosaretsky, Methodological foundations of the system of psychological and pedagogical support. Electronic resource. access mode: http://humanities.edu.ru.

[4] I.S. Yakimanskaya, Pedagogical psychology. Main problems. /I. S. Yakimanskaya, - M.MODEK, 2008

[5] G.M. Kiselev, Modern information technologies. Laboratory practical work. For students of direction 050400 - Psychological and pedagogical education. Moscow: publishing house IPA-PRESS, 2013 $124 \mathrm{p}$. 
[6] E.A. Kozyreva, Theoretical and technological aspects of psychological and pedagogical support of children, their teachers and parents // School psychologist, 2001, No 33.

[7] World University Rankings 2016-2017 / Times Higher Education. https://www.timeshighereducation.com/world-universityrankings/2017/world-

ranking\#!/page/0/length/25/sort_by/rank/sort_order/asc/cols/stats. [45]

[8] World University Rankings 2016-2017 / Times Higher Education. https://www.timeshighereducation.com/world-universityrankings/2017/world-

ranking\#!/page/0/length/25/sort_by/rank/sort_order/asc/cols/stats. [47]

[9] TIMSS - Trends in Mathematics and Science Study, International study on the evaluation of the quality of mathematical and natural science education, conducted by an international educational center IEA's TIMSS \&PIRLS (Boston, CШA). TIMSS 2015 International Results Report / TIMSS \& PIRLS International Study Center. - 2015. results/download-center/

http://timssandpirls.bc.edu/timss2015/international-

[10] Yulia Romanova, Anna Egorenko, Scientific Methodological Approach to Effective Contract Assessment. Advances in Social Science, Education and Humanities Research. Proceedings of the 2017 International Conference on Culture, Education and Financial Development of Modern Society (ICCESE 2017) Copyright @ 2017 , the Authors. Published by Atlantis Press. This is an open access article under the CC BY-NC license Publication date May 2017 ISBN 978-94-6252-330-2 ISSN 2352-5398 doi:10.2991/iccese-17.2017.24 See for details: https://creativecommons.org/licenses/bync/4.0/ http://www.atlantis-

press.com/php/pub.php?publication=iccese- 17 . 